\title{
Comparison of laparoscopic versus open gastrectomy for advanced gastric cancer: an updated meta-analysis
}

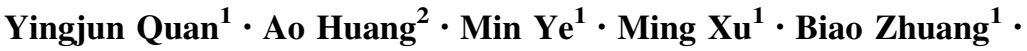 \\ Peng Zhang ${ }^{1} \cdot$ Bo Y $\mathbf{u}^{1} \cdot$ Zhijun Min ${ }^{1}$
}

Received: 25 September 2014/ Accepted: 13 July 2015/Published online: 28 July 2015

(c) The International Gastric Cancer Association and The Japanese Gastric Cancer Association 2015

\begin{abstract}
Background Laparoscopic gastrectomy (LG) has been used as an alternative to open gastrectomy (OG) to treat early gastric cancer. However, the use of LG for advanced gastric cancer (AGC) has been in debate.

Methods Literature retrieval was performed by searching PubMed, EMBASE, and the Cochrane library up to July 2014. Potential studies comparing the surgical effects between LG with OG were evaluated and data were extracted accordingly. Meta-analysis was carried out using RevMan. The pooled risk ratio and weighted mean difference (WMD) with $95 \%$ confidence interval $(95 \% \mathrm{CI})$ were calculated.

Results Overall, 26 studies were included in this metaanalysis. LG had some advantages over OG, including shorter hospitalization (WMD, $-3.63,95 \% \mathrm{CI},-4.66$ to $-2.60 ; P<0.01$ ), less blood loss (WMD, $-161.37,95 \%$ CI, -192.55 to $-130.18 ; P<0.01)$, faster bowel recovery (WMD, $-0.78,95 \% \mathrm{CI},-1.05$ to $-0.50 ; P<0.01$ ), and earlier ambulation (WMD, $-0.95,95 \% \mathrm{CI},-1.47$ to $-0.44 ; P<0.01)$. In terms of surgical and oncological
\end{abstract}

Ao Huang is co-first author.

Ao Huang

surgeonhuang@yeah.net

Yingjun Quan

qyjasmine@126.com

Zhijun Min

minzhijun@126.com

1 Department of Gastrointestinal Surgery, Shanghai Pudong Hospital, Fudan University Pudong Medical Center, Shanghai 201399, China

2 Liver Cancer Institute, Zhongshan Hospital, Fudan University, Shanghai 200032, China safety, LG could achieve similar lymph nodes (WMD, $-0.49,95 \% \mathrm{CI},-1.78$ to $0.81 ; P=0.46$ ), a lower complication rate [odds ratio (OR), $0.71,95 \% \mathrm{CI}, 0.59$ to 0.87 ; $P<0.01$ ], and overall survival (OS) and disease-free survival (DFS) comparable to OG.

Conclusions For AGCs, LG appeared comparable with OG in short- and long-term results. Although more time was needed to perform LG, it had some advantages over OG in achieving faster postoperative recovery. Ongoing trials and future studies could help to clarify this controversial issue.

Keywords Laparoscopic gastrectomy · Open gastrectomy $\cdot$ Advanced gastric cancer $\cdot$ Meta-analysis

\section{Introduction}

Gastric cancer is the fourth most frequently occurring cancer and the second most common cause of cancer-related death worldwide, accounting for $8 \%$ of total and $10 \%$ of annual cancer deaths globally [1, 2]. Despite advances in chemoradiotherapy and targeted therapy, surgery remains the only curative method for gastric cancer [3]. Complete removal of macroscopic and microscopic malignant lesions along with regional or extended lymphadenectomy represents the optimal treatment of choice for resectable localized gastric cancer.

For a long time, conventional open gastrectomy (OG) has been the only choice for gastric cancer surgery. In recent decades, however, minimally invasive surgeries, namely, endoscopic and laparoscopic procedures, have been increasingly used. For early gastric cancer (EGC) patients with negligible risk of lymph node (LN) metastasis, endoscopic surgeries such as endoscopic mucosal 
resection (EMR) and endoscopic submucosal dissection (ESD) have become the primary treatment of choice in Japan and Korea [4]. Of note, laparoscopic gastrectomy (LG) for EGC was first introduced by Kitano in 1994 [5]; since then, it has undergone rapid development and is widely used to treat EGC nowadays. Compared to OG, LG is associated with less blood loss, fewer surgical complications, faster bowel function recovery, shorter hospital stay, and an equivalent rate of postoperative tumor recurrence [6-8]. Although the long-term oncological effects of LG for EGC still need to be validated by two ongoing phase III trials $[9,10]$, laparoscopic surgery for EGC is largely accepted and increasingly used in East Asia (China, Japan, and Korea).

However, the use of LG for advanced gastric cancer (AGC) has been controversial. The oncological safety of LG in AGC treatment has not been thoroughly evaluated, and it is largely unknown whether the long-term follow-up of LG is comparable with that of OG. Nevertheless, LG is attracting more and more attraction and is widely used for AGC by surgeons in East Asia, despite the lack of evidence concerning its safety and efficiency. To this end, we compiled this updated metaanalysis to compare the intraoperative effects, morbidity and mortality, and short- and long-term results between LG and OG, trying to find some proof for the use of LG in AGC treatment.

\section{Methods}

\section{Literature search}

A comprehensive literature search strategy was made by retrieving the keywords "advanced gastric cancer", "laparoscopic gastrectomy", and "open gastrectomy" in the electronic databases of PubMed, EMBASE, and the Cochrane library from the inception until July 2014. Only studies published in English were included. To avoid omitting any potential studies, we manually checked the references of included literature. Two authors (Quan and Huang) individually conducted the literature search and cross-checked their search results. Full texts of included studies were downloaded accordingly from these databases.

\section{Study selection}

Duplicated search results were first excluded. Studies were included in this meta-analysis if they met the following criteria: having compared the two surgical procedures, namely, LG and OG; having reported detailed/available data of the surgical results, including short- and/or longterm results; patients in the studies were diagnosed with AGC or data of AGC patients were presented separately from EGC patients. If there were two or more studies derived from the same authors or centers, only the study with the largest sample size/highest quality or the more recent one was chosen. In case of studies from the same authors or centers with different patients enrolled, they were all included. Conference abstracts were deleted because no detailed information could be retrieved. Study selection was done by two authors (Ye and $\mathrm{Xu}$ ) separately, and selection results were mutually checked. In case of discrepancies, a third author (Min) was asked to discuss to reach a consensus.

\section{Data extraction}

Data were extracted by two authors (Zhuang and Zhang) independently using predefined standards and crosschecked. Data extracted included study characteristics (author, publication year, region, study period, design, case number), patient demographics (age, gender, tumor stage), and surgical results (operation time, intraoperative blood loss, retrieved LNs, length of hospital stay, time to first flatus, onset of oral diet, time to ambulation, perioperative complication and death rates, tumor size, proximal and distal resection margin distance, tumor recurrence, and overall and disease-free survival). Perioperative complications were categorized as surgical or nonsurgical complications using previously reported criteria [11]. Corresponding authors were contacted if further information was needed. In case of discrepancies, a third author $(\mathrm{Yu})$ was asked to discuss until a consensus was reached.

\section{Statistical analysis}

This meta-analysis was conducted under the guidelines of preferred reporting items for systematic reviews and metaanalyses (PRISMA) 2009 [12]. Data analyses were performed with the software Review Manager (RevMan) Version 5.2 (http://ims.cochrane.org/revman). Generally, because of the heterogeneity and the different risk profiles of patients operated on by surgeons from different centers, the random effects model was first employed to calculate the weighted mean difference (WMD) (continuous data) or risk ratio (dichotomous data) and their $95 \%$ confidence interval $(95 \%$ CI). Heterogeneity was calculated by Cochran's $\chi^{2}$ and the $I^{2}$ test. If no significant heterogeneity was observed among the included studies $(P>0.1$, $\left.I^{2}<50 \%\right)$, the fixed effect model was used. Publication bias was evaluated by a funnel plot. For all analyses, $P<0.05$ was considered statistically significant. 


\section{Results}

\section{Outcome of literature search and study selection}

The literature search strategy identified a total of 501 studies. Ninety-two non-English written publications and 64 repetitive search items were first excluded; 268 studies were deleted on the basis of reviewing the titles and abstracts. After reading the full texts of the remaining papers, 24 studies [13-36] were removed as they only reported the outcomes of LG for AGC whereas no controlled or matched cases treated by OG were available. Among the remaining articles, 19 studies [37-55] were excluded because EGC cases were mixed with AGCs in the cohort studies and data on AGCs were not extractable. Eight studies were further deleted for the following reasons: 2 studies were ongoing randomized controlled trials (RCTs) that only described study design and patient enrollment criteria without results reported [56, 57]; 2 studies had overlapped enrollments with former research [58, 59]; 1 study reported incomplete data that were not suitable for analysis [60]; and 3 studies discussed other issues irrelevant to the topic of this meta-analysis [61-63]. Finally, a total of 26 studies that compared the short-term and/or long-term results of AGCs treated by LG with those of OG were included [64-89]. Figure 1 depicts the literature search and selection process of this meta-analysis.

Initial literature search identified a total of 501 articles based on the terms: "advanced gastric cancer", "laparoscopic gastrectomy", and "open gastrectomy"

92 non-English written papers and 64 duplicate searching items were excluded

345 studies left for topic examination

268 papers were deleted for unrelated title and abstract

77 articles left for further evaluation

51 studies were further deleted:

-24 reported LG for AGCs without controls

-19 had mixed cases with EGCS

-2 were trial protocols; 2 had duplicate data; 1 had incomplete data; 3 had unrelated results.

26 studies were finally included

Fig. 1 Flowchart of literature search and study selection process

\section{Characteristics of included studies}

Overall, a total of 5061 AGC patients were included in this meta-analysis; among them, $2193(43.3 \%)$ patients were treated by LG and 2868 (56.7 \%) patients underwent OG. For each study, the demographics and clinicopathological characteristics of patients treated by LG and OG did not differ from each other. Of the 26 included articles, 10 studies originated from China, 7 from Korea, 5 from Japan, 2 from Italy, and 1 each from Chile and Canada, respectively. The research period ranged from 1997 to 2011, and most studies were published within the past 3 years. Case numbers varied among included studies, from as few as 18 to as many as 799 . Distal and total gastrectomy were frequently used surgical options, although proximal and subtotal gastrectomy were also adopted in some studies. Gastrointestinal tract reconstruction modalities included Billroth-I/II, Roux-en-Y anastomosis, jejunal pouch interposition, esophagogastrostomy, and esophagojejunostomy. None of the studies had used neoadjuvant chemoradiotherapy, and postoperative chemoradiotherapy was prescribed for some of the patients in some studies. Most studies reported follow-up ranging from 15 months to 5 years. Detailed information on study characteristics is shown in Table 1.

\section{Comparison of intraoperative effects}

We first compared the intraoperative results between LG and OG. Consistent with the pronounced benefits of laparoscopic surgery, the estimated blood loss was much less for LG than OG (WMD, -161.37, $95 \% \mathrm{CI},-192.55$ to $-130.18 ; P<0.01)$. In contrast, the mean operation time of LG was longer than OG (WMD, 51.86, $95 \% \mathrm{CI}$, 35.82-67.91; $P<0.01)$. In terms of dissected LNs, LG could achieve the same radical dissection effect as OG (WMD, $-0.49,95 \% \mathrm{CI},-1.78$ to $0.81 ; P=0.46$ ) (Fig. 2); specifically, we compared studies that adopted D2 LN dissection, which showed that LG had similar LN production with $\mathrm{OG}$ as well (WMD, $-0.69,95 \% \mathrm{CI}$, -2.31 to $0.93 ; P=0.41)$. Furthermore, both procedures yielded comparable proximal (WMD, $-0.10,95 \% \mathrm{CI}$, -0.38 to $0.18 ; P=0.49$ ) and distal (WMD, $0.14,95 \% \mathrm{CI}$, -0.01 to $0.29 ; P=0.06)$ resection margin distance; however, the average tumor size in LG was slightly larger than that in OG (WMD, $-0.35,95 \% \mathrm{CI},-0.63$ to -0.07 ; $P=0.02$ ). Results of analyses of intraoperative effects are shown in Table 2.

\section{Analyses of short-term results}

The advantages of laparoscopic surgery over open surgery also included less pain, shorter hospitalization, quicker 


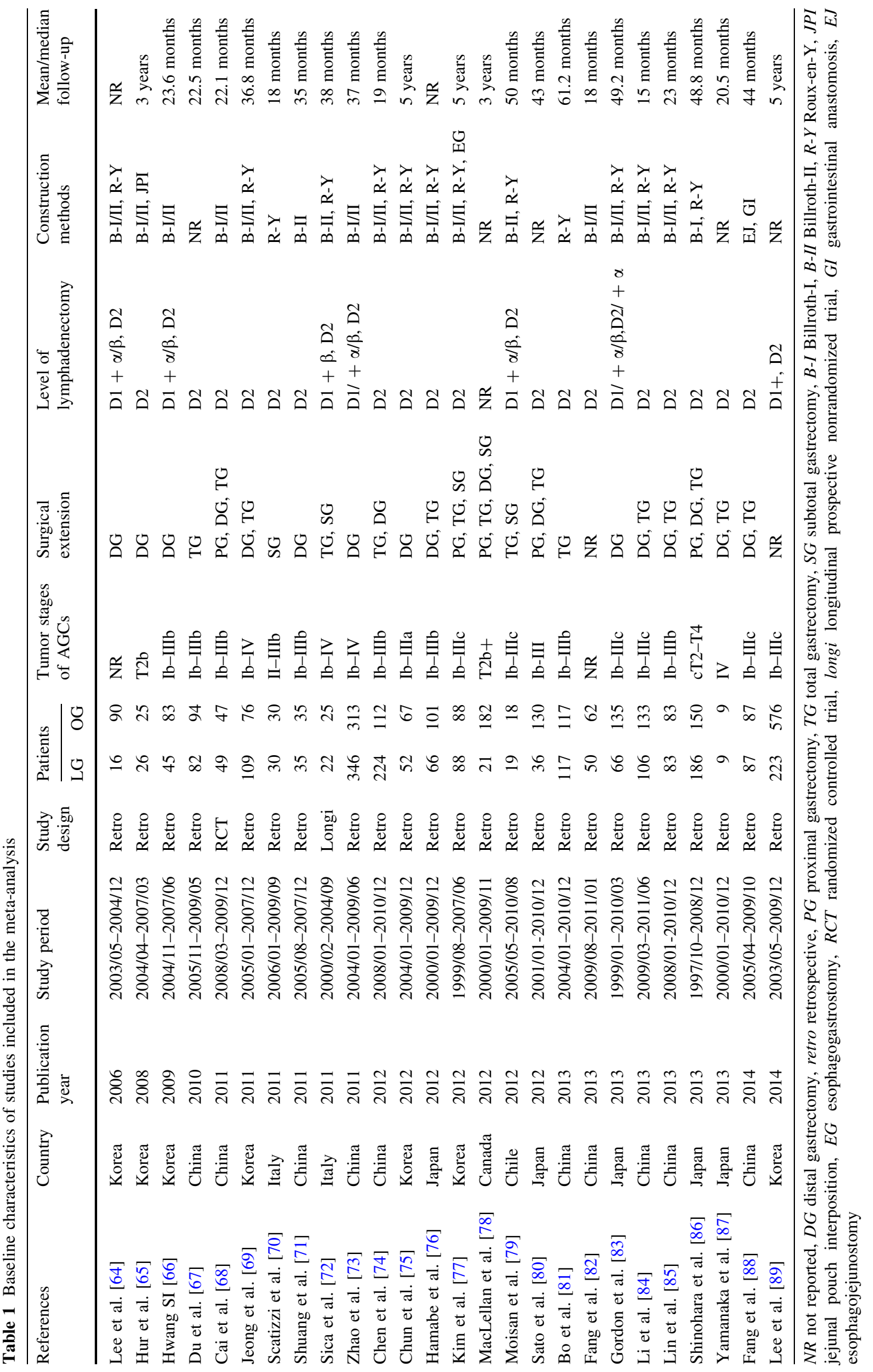




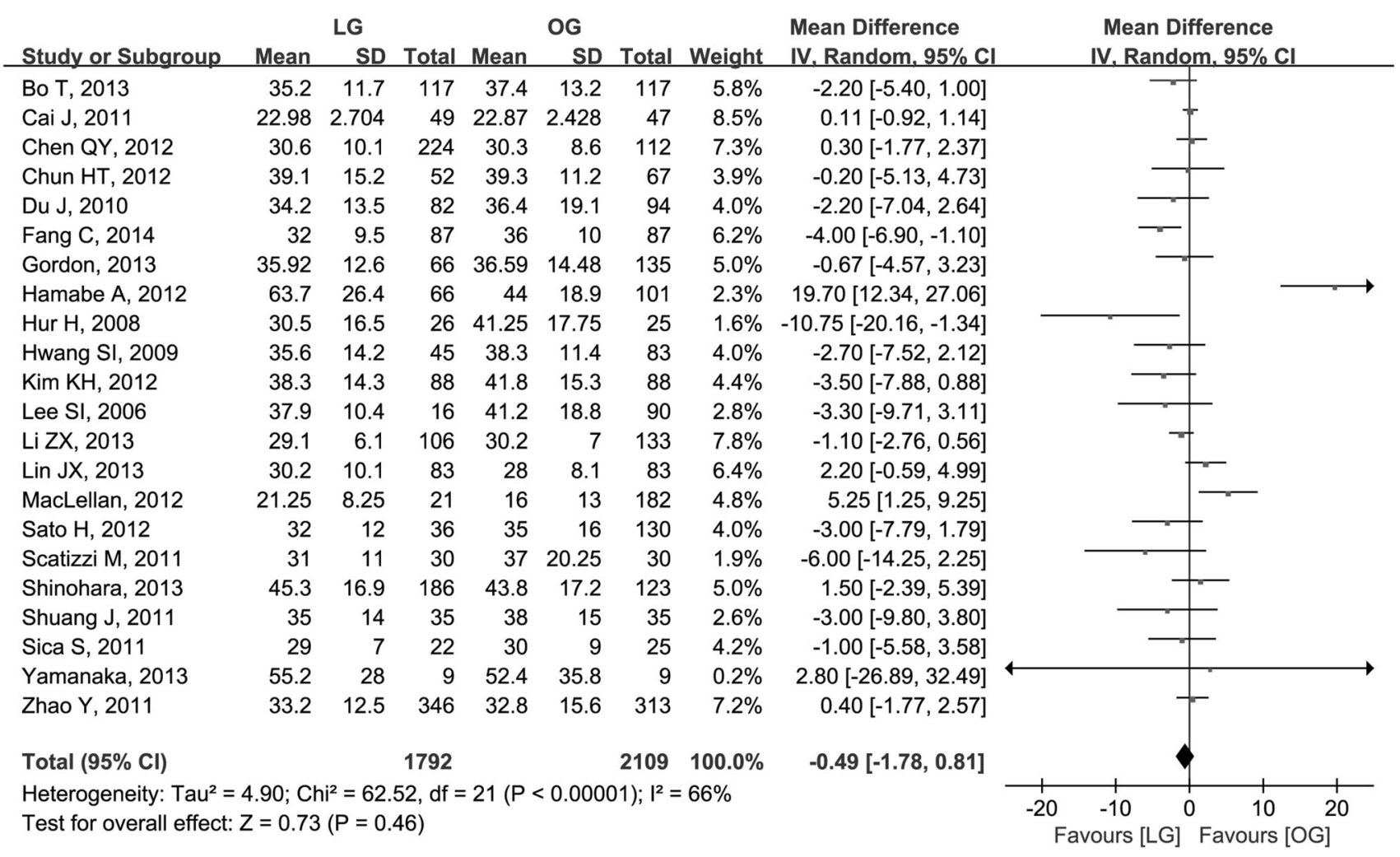

Fig. 2 Forest plot showing the meta-analysis results of retrieved lymph nodes. The estimates of the weighted mean difference in each study correspond to the middle of each square and the horizontal line gives the $95 \%$ CI. Pooled effect is represented by the middle of the solid diamond

Table 2 Comparisons of intraoperative surgical effects

\begin{tabular}{|c|c|c|c|c|c|c|}
\hline \multirow[t]{2}{*}{ Outcomes } & \multirow{2}{*}{$\begin{array}{l}\text { Included } \\
\text { studies }\end{array}$} & \multicolumn{2}{|c|}{ Patients } & \multirow{2}{*}{$\begin{array}{l}\text { Heterogeneity } \\
\left(I^{2}, P\right)\end{array}$} & \multirow{2}{*}{$\begin{array}{l}\text { Overall effect WMD } \\
(95 \% \text { CI })\end{array}$} & \multirow[t]{2}{*}{$P$ value } \\
\hline & & LG & OG & & & \\
\hline Estimated blood loss & 16 & 1563 & 1627 & $88 \%,<0.01$ & $-161.37(-192.55,-130.18)$ & $<0.01$ \\
\hline Operation time & 20 & 1783 & 1874 & $94 \%,<0.01$ & $51.86(35.82,67.91)$ & $<0.01$ \\
\hline Retrieved LNs & 22 & 1792 & 2109 & $64 \%,<0.01$ & $-0.49(-1.78,0.81)$ & 0.46 \\
\hline Retrieved LNs of D2 lymphadenectomy & 16 & 1276 & 1281 & $72 \%,<0.01$ & $-0.69(-2.31,0.93)$ & 0.41 \\
\hline Tumor size & 14 & 1277 & 1233 & $67 \%,<0.01$ & $-0.35(-0.63,-0.07)$ & 0.02 \\
\hline Proximal resection margin distance & 8 & 775 & 805 & $58 \%, 0.02$ & $-0.10(-0.38,0.18)$ & 0.49 \\
\hline Distal resection margin distance & 5 & 618 & 624 & $0 \%, 0.86$ & $0.14(-0.01,0.29)$ & 0.06 \\
\hline
\end{tabular}

$L G$ laparoscopic gastrectomy, $O G$ open gastrectomy, $L N$ lymph node, $W M D$ weighted mean difference

bowel function recovery, and earlier resumption of body movement. In agreement with this, we found patients undergoing LG had shorter hospital stay (WMD, -3.63, $95 \% \mathrm{CI},-4.66$ to $-2.60 ; P<0.01)$, shorter mean time to first flatus (WMD, $-0.78,95 \% \mathrm{CI},-1.05$ to -0.50 ; $P<0.01$ ), and resumed oral intake much earlier (WMD, $-0.89,95 \% \mathrm{CI},-1.20$ to $-0.59 ; P<0.01)$ than those undergoing OG. Also, patients treated with LG needed less time to ambulation than those with OG (WMD, -0.95 , $95 \% \mathrm{CI},-1.47$ to $-0.44 ; P<0.01)$. The perioperative complication rates were also compared: overall complication rate for LG was $13.2 \%$, significantly lower than the rate of $18.0 \%$ of OG (OR, $0.71,95 \% \mathrm{CI}$, 0.59-0.87; $P<0.01$ ) (Fig. 3). To be specific, the rates of surgical complications, including leakage, bleeding, wound infection, and anastomotic stricture (OR, 0.69, $95 \% \mathrm{CI}$, $0.53-0.88 ; P=0.003$ ), and medical complications such as respiratory or cardiovascular events, deep venous thrombosis, pulmonary embolism, and nonsurgical infections (OR, 0.51, $95 \% \mathrm{CI}, 0.32-0.81 ; P=0.004)$, were both lower in the LG patients than in OG patients. In terms of mortality, no significant differences were seen between the 


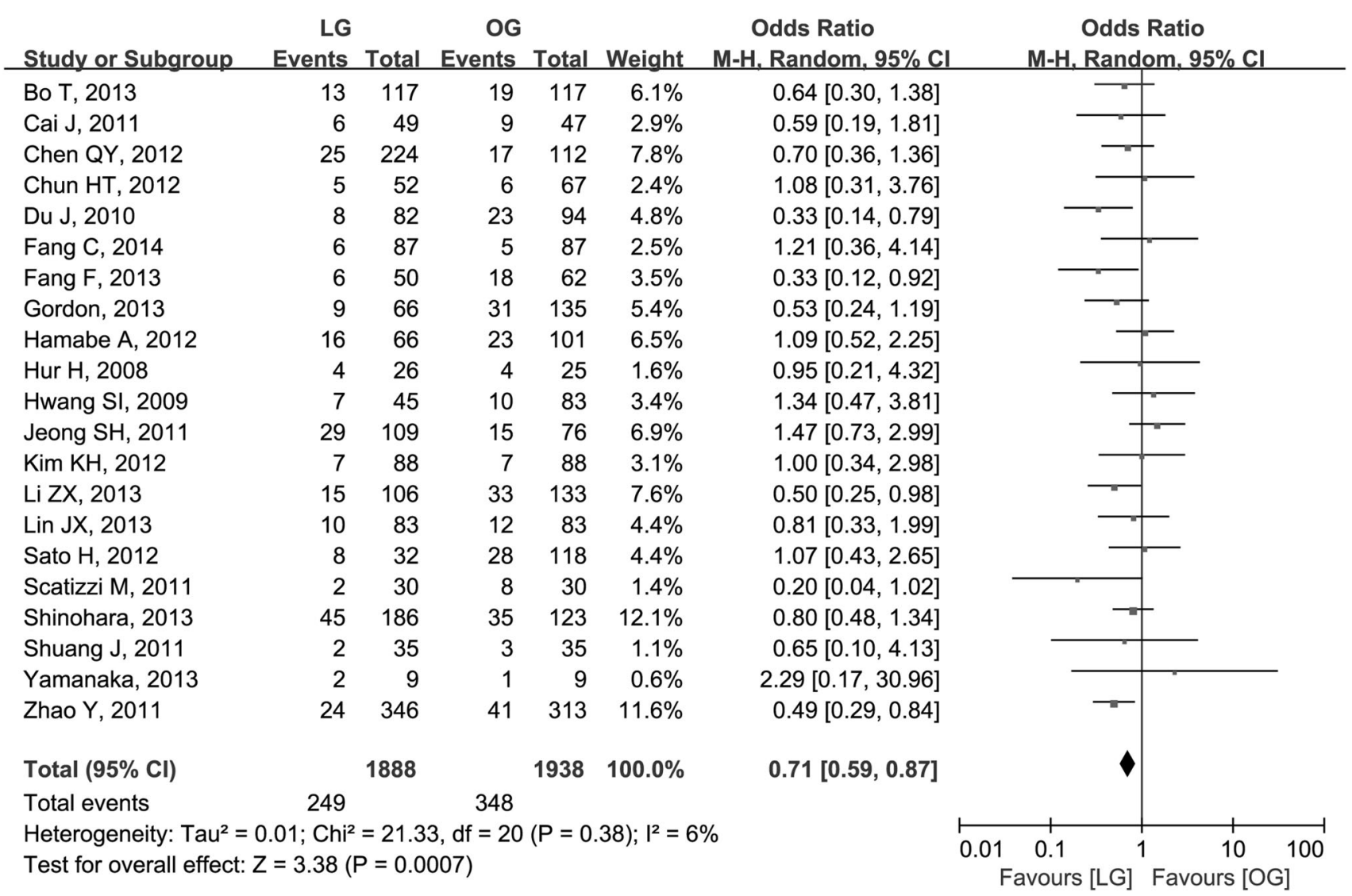

Fig. 3 Forest plot of pooled odds ratio of overall complication

Table 3 Comparisons of short-term results

\begin{tabular}{|c|c|c|c|c|c|c|}
\hline \multirow[t]{2}{*}{$\overline{\text { Outcomes }}$} & \multirow[t]{2}{*}{ Included studies } & \multicolumn{2}{|c|}{ Patients } & \multirow[t]{2}{*}{ Heterogeneity $\left(I^{2}, P\right)$} & \multirow[t]{2}{*}{ Overall effect WMD/RR (95\% CI) } & \multirow[t]{2}{*}{$P$ value } \\
\hline & & LG & OG & & & \\
\hline Hospital stay & 18 & 1593 & 1652 & $86 \%,<0.01$ & $-3.63(-4.66,-2.60)$ & $<0.01$ \\
\hline First flatus & 15 & 1373 & 1398 & $89 \%,<0.01$ & $-0.78(-1.05,-0.50)$ & $<0.01$ \\
\hline Oral diet & 12 & 1237 & 1165 & $72 \%,<0.01$ & $-0.89(-1.20,-0.59)$ & $<0.01$ \\
\hline Ambulation & 9 & 1162 & 1002 & $97 \%,<0.01$ & $-0.95(-1.47,-0.44)$ & 0.0003 \\
\hline Overall complication & 21 & 1888 & 1938 & $6 \%, 0.38$ & $0.71^{\mathrm{a}}(0.59,0.87)$ & 0.0007 \\
\hline Surgical complication & 13 & 1404 & 1318 & $0 \%, 0.61$ & $0.69^{\mathrm{a}}(0.53,0.88)$ & 0.003 \\
\hline Medical complication & 11 & 1023 & 970 & $8 \%, 0.37$ & $0.51^{\mathrm{a}}(0.32,0.81)$ & 0.004 \\
\hline Mortality & 11 & 1230 & 1225 & $0 \%, 0.89$ & $0.67^{\mathrm{a}}(0.25,1.77)$ & 0.42 \\
\hline
\end{tabular}

$L G$ laparoscopic gastrectomy, $O G$ open gastrectomy, $W M D$ weighted mean difference, $R R$ risk ratio

${ }^{\text {a }} \mathrm{RR}$

two procedures (OR, 0.67, $95 \% \mathrm{CI}, 0.25-1.77 ; P=0.42)$. Table 3 summarizes the comparison outcomes of shortterm results between LG and OG.

\section{Analyses of long-term effects}

The long-term results including recurrence, overall survival (OS), and disease-free survival (DFS) were analyzed.
Fourteen studies reported data on tumor recurrence, with no significant heterogeneity observed. The recurrence rate in LG was $27.1 \%$, which was significantly lower than the rate of $30.6 \%$ in OG (OR, 0.80, 95\% CI, 0.66-0.96; $P=0.02)$. In all, 24 studies [65-75, 77-89] reported longterm follow-up ranging from 1 year to 5 years. Four studies [73, 74, 82, 85] reported 1-year OS; 7 studies [65, $68,70,73,78,79,82]$ reported 3-year OS, and 9 [72, 73, 
Table 4 Comparisons of longterm results

\begin{tabular}{lcrrllll}
\hline Outcomes & Included studies & \multicolumn{2}{l}{ Patients } & & $\begin{array}{l}\text { Heterogeneity } \\
\left(I^{2}, P\right)\end{array}$ & $\begin{array}{l}\text { Overall effect } \\
\text { RR }(95 \% \text { CI })\end{array}$ & $P$ value \\
\cline { 2 - 4 } & & \multicolumn{1}{c}{ LG } & OG & & & \\
\hline Recurrence & 14 & 1184 & 1391 & $0 \%, 0.69$ & $0.80(0.66,0.96)$ & 0.02 \\
1-year OS & 4 & 674 & 543 & $0 \%, 0.88$ & $0.98(0.68,1.40)$ & 0.90 \\
3-year OS & 7 & 527 & 661 & $0 \%, 0.83$ & $1.19(0.92,1.53)$ & 0.18 \\
5-year OS & 9 & 1008 & 992 & $0 \%, 0.62$ & $1.20(0.99,1.46)$ & 0.06 \\
3-year DFS & 3 & 66 & 225 & $58 \%, 0.09$ & $1.25(0.44,3.55)$ & 0.67 \\
5-year DFS & 5 & 773 & 712 & $13 \%, 0.33$ & $1.22(0.95,1.57)$ & 0.11 \\
\hline
\end{tabular}

$L G$ laparoscopic gastrectomy, $O G$ open gastrectomy, $O S$ overall survival, $D F S$ disease-free survival, $R R$ risk ratio
$75-77,81,83,86,88]$ reported 5-year OS. No significant differences were seen in 1-, 3-, or 5-year OS between LG and OG [1-year: risk ratio $(\mathrm{RR})=0.98,95 \%$ CI $0.68-1.40, \quad P=0.90 ; \quad 3$-year: $\quad \mathrm{RR}=1.19, \quad 95 \% \quad \mathrm{CI}$ $0.92-1.53, \quad P=0.18 ; \quad 5$-year: $\quad \mathrm{RR}=1.20, \quad 95 \% \quad \mathrm{CI}$ $0.99-1.46, P=0.06]$. Regarding DFS, $3[65,78,79]$ studies reported 3-year DFS and 5 studies [73, 76, 77, 86, 88] reported 5-year DFS. The 3-year DFS of LG and OG were $65.2 \%$ and $58.2 \%$, respectively (OR, $1.25,95 \% \mathrm{CI}$, $0.44-3.55 ; P=0.67)$; the 5-year DFS of LG and OG were $60.7 \%$ and $57.9 \%$, respectively (OR, 1.22, $95 \% \mathrm{CI}$, $0.95-1.57 ; P=0.11)$. Meta-analysis results of long-term effects are presented in Table 4.

\section{Discussion}

Laparoscopic surgery has several advantages over conventional open surgery, such as faster recovery, shorter hospitalization, less pain, and less blood loss [90]. In the past two decades, the use of laparoscopy has been continuously increasing, and its indications have also expanded, from benign diseases to malignant tumors [91, 92]. Laparoscopic gastrectomy has long been used to treat EGC, and in the past decade, attention has been paid to the feasibility and safety of LG for AGC. Although several clinical trials have been initiated to evaluate the effectiveness of LG $[9,10,56,57]$, currently we do not have enough evidence to support this surgical procedure in AGC management. To this end, we conducted this meta-analysis trying to find some clues.

In the current study, we observed that LG demonstrated several advantages when it was used for AGC treatment. Compared to AGC patients treated by OG, patients in the LG group showed significantly shorter hospital stay, less blood loss, faster postoperative recovery, and earlier ambulation. These advantages were in agreement with the conceptions of fast track surgery and benefits to AGC patient recovery [93, 94]. We also found longer operation time for LG in this study. Although laparoscopy could provide a wide operation field, restriction in trocar number [95], insufficient training [96], and lack of tactile feedback [97] made the surgical process less flexible and more complicated than open surgery. For AGC, gastrectomy combined with D1 or D2 lymphadenectomy was more difficult than gastrectomy alone, which possibly resulted in the longer operation time in LG. However, according to studies that reported the learning curve of LG in AGCs, the operation time could reach a plateau after about 40 cases, and by experienced surgeons, LG could be done as quickly as OG [98-100].

Another major finding that supported the use of LG for AGC was that the surgical and oncological safety of LG were comparable with or even superior to those of OG. In the present study, we found both the overall and specific complication rates of LG were much lower. As already mentioned, LG has the inherent benefit of minimal invasiveness, and this certainly reduced the chance of causing massive tissue and organ damage during an operation, which would result in fewer surgical complications as a consequence. Similarly, a smaller incision and the use of techniques such as hemolock, titanium clip, and ultrasonic scalpel reduced the incidence of wound infection and bleeding. Moreover, under laparoscopy, surgeons could sufficiently dissect the duodenum to make anastomosis without tension so as to avoid stomal leakage and stricture. We also observed fewer medical complications in LG than OG. For postoperative inpatients, medical complications such as respiratory or cardiovascular events, deep venous thrombosis, and pulmonary embolism are potential threats. In this study, the medical complication rate of LG patients was $4.1 \%$, significantly lower than the rate of $7.8 \%$ of OG. This change could also be attributed to the benefits of laparoscopic surgery because patients needed less hospitalization time to recovery, which reduced the risk of acquiring a nosocomial infection [101]; further, LG patients were able to resume body movements earlier than OG patients, thus lowering the risk of hypostasis and deep venous thrombosis [102].

In terms of oncological safety, LG achieved comparable results with OG. To reduce the possibility of recurrence and 
metastasis, adequate LN dissection is important in gastric cancer treatment [103] and confers survival benefits for gastric patients at specific stages [104]. One major concern about the use of laparoscopy in AGC was its efficiency for lymphadenectomy: whether this technique could harvest enough LNs for pathology evaluation and reach the same radicality as open surgery remained controversial. In this meta-analysis, we found LG could retrieve as many LNs as did OG, possibly resulting from the increasing use of LG and improvements in laparoscopy facilities and surgical methodology. Importantly, a recent study by Lee et al. showed that for experts of OG, in cases in which surgical time extension could be accepted willingly, the radicality in lymphadenectomy could be also achieved even during the learning period of LG [105]. Specially, D2 lymphadenectomy is generally recommended as the standard procedure to treat AGCs in East Asia [106]. Successful D2 lymphadenectomy is thus an essential part of radical resection for AGC [107]. We found the number of LNs retrieved in LG with D2 lymphadenectomy did not differ from that of OG, suggesting LG had lymphadenectomy effectiveness comparable with that of OG.

Resection margin distance is another variable that affects oncological results. It is well established that complete removal of tumor mass is the primary goal of radical resection and that positive resection margin correlates with increased risk of local recurrence and decreased OS and DFS in many cancers [108]. Recent studies suggested that surgical margin status could be considered as an independent prognostic factor for GC patients [109, 110] and that sufficient distance between resection margin and tumor edge assured the complete removal of the tumor tissues and also decreased the risk of positive resection margin [111]. Thus, evaluation of resection margin distance could partially reflect the curability of surgical procedures. Hereby, we found both the proximal and distal resection margin distances did not differ between LG and OG, indicating LG possessed curability and oncological safety comparable to that of OG. It is proposed that tumor size should also be recommended as an important clinicopathological factor to enhance the accuracy of the prognostic prediction of GC patients [112]. Previous metaanalyses rarely made comparisons about this factor. Unexpectedly, we observed that the tumor size in LG was much larger than that of OG, which suggested a prognostic benefit of LG. Although moderate heterogeneity was seen among the included studies, this difference led us to believe LG might have better curability than OG and that future studies should pay additional attention to this field.

The long-term results including OS, DFS, and recurrence could be directly used to evaluate the effects of surgical procedures. In this study, different types of survival were similar between LG and OG. The 1-, 3-, and 5-year OS and 3- and 5-year DFS were comparable, indicating the treatment effects of LG at least were not inferior to OG. Interestingly, less recurrence was observed in LG, which contradicted the results of a former meta-analysis [113], and we believed this difference might be attributed to the studies included for analysis. The presented study included several recently published trials and also excluded some studies with both EGC and AGC patients, which enlarged the case pool and eliminated confounding bias at the same time. Port-site metastasis is proposed to be one disadvantage of laparoscopic surgery and could occur in different kinds of malignant cancers [114]; moreover, portsite metastasis might indicate a harbinger of progressive disease [115]. Although it occurred rarely in LG for EGCs, the incidence of port-site metastasis after LG in AGCs is largely unknown [116]. In this meta-analysis, only two studies reported port-site metastasis $[66,73]$. This type of complication could be avoided if surgeons would carefully perform LG with standard laparoscopic procedures, minimize tumor touch, and protect the incision with a plastic bag during tumor extraction [117].

Some limitations exist that should not be neglected when interpreting the conclusions of this study. First, most studies included in this meta-analysis were performed retrospectively whereas only one prospective RCT was included. Generally, RCTs are much more suitable than other types of trials for meta-analysis; with only one RCT included in this meta-analysis, the quality and confidence level might be questioned. Second, there was no analysis of survival based on chemoradiotherapy status. It is well known that chemoradiotherapy following surgery is the standard treatment for AGC patients; thus, the long-term follow-up results of LG and OG could be better evaluated if patients were stratified by chemoradiotherapy status or modality. Third, the case volumes of the included studies varied greatly, which could significantly affect the results of surgical procedures and lead to high heterogeneity among studies. In such a case, comparisons of surgical results would be influenced by surgeons' experience. Future trials with prospective design and multi-center participation are needed.

Conclusively, the current study presented convincing evidence to show that LG could achieve comparable results with OG for AGC patients in terms of short- and long-term effects. Moreover, LG demonstrated some advantages over OG, including faster recovery and shorter hospitalization time. Although ongoing RCTs have not yielded clear answers on this issue up to now, based on the results of this and other former meta-analyses, as well as previous trials, we believe AGC could be safely treated with LG by experienced surgeons under standard laparoscopic principles. 


\section{References}

1. Guggenheim DE, Shah MA. Gastric cancer epidemiology and risk factors. J Surg Oncol. 2013;107:230-6.

2. Siegel R, Ma J, Zou Z, Jemal A. Cancer statistics, 2014. CA Cancer J Clin. 2014;64:9-29.

3. Saka M, Morita S, Fukagawa T, Katai H. Present and future status of gastric cancer surgery. Jpn $\mathrm{J}$ Clin Oncol. 2011;41:307-13.

4. Shen L, Shan YS, Hu HM, Price TJ, Sirohi B, Yeh KH, et al. Management of gastric cancer in Asia: resource-stratified guidelines. Lancet Oncol. 2013;14:e535-47.

5. Kitano S, Iso Y, Moriyama M, Sugimachi K. Laparoscopy-assisted Billroth I gastrectomy. Surg Laparosc Endosc. 1994;4: 146-8.

6. Kitano S, Shiraishi N, Fujii K, Yasuda K, Inomata M, Adachi Y. A randomized controlled trial comparing open vs. laparoscopyassisted distal gastrectomy for the treatment of early gastric cancer: an interim report. Surgery (St. Louis). 2002;131: S306-11.

7. Hayashi H, Ochiai T, Shimada H, Gunji Y. Prospective randomized study of open versus laparoscopy-assisted distal gastrectomy with extraperigastric lymph node dissection for early gastric cancer. Surg Endosc. 2005;19:1172-6.

8. Lee JH, Han HS, Lee JH. A prospective randomized study comparing open vs. laparoscopy-assisted distal gastrectomy in early gastric cancer: early results. Surg Endosc. 2005;19:168-73.

9. Kim HH, Han SU, Kim MC, Hyung WJ, Kim W, Lee HJ, et al. Prospective randomized controlled trial (phase III) to comparing laparoscopic distal gastrectomy with open distal gastrectomy for gastric adenocarcinoma (KLASS 01). J Korean Surg Soc. 2013;84:123-30.

10. Nakamura K, Katai H, Mizusawa J, Yoshikawa T, Ando M, Terashima M, et al. A phase III study of laparoscopy-assisted versus open distal gastrectomy with nodal dissection for clinical stage IA/IB gastric cancer (JCOG0912). Jpn J Clin Oncol. 2013;43:324-7.

11. Grobmyer SR, Pieracci FM, Allen PJ, Brennan MF, Jaques DP. Defining morbidity after pancreaticoduodenectomy: use of a prospective complication grading system. J Am Coll Surg. 2007;204:356-64.

12. Moher D, Liberati A, Tetzlaff J, Altman DG. Preferred reporting items for systematic reviews and meta-analyses: the PRISMA statement. J Clin Epidemiol. 2009;62:1006-12.

13. Uyama I, Sugioka A, Fujita J, Komori Y, Matsui H, Hasumi A. Laparoscopic total gastrectomy with distal pancreatosplenectomy and D2 lymphadenectomy for advanced gastric cancer. Gastric Cancer. 1999;2:230-4.

14. Uyama I, Sugioka A, Matsui H, Fujita J, Komori Y, Hasumi A. Laparoscopic D2 lymph node dissection for advanced gastric cancer located in the middle or lower third portion of the stomach. Gastric Cancer. 2000;3:50-5.

15. Uyama I, Sugioka A, Sakurai Y, Komori Y, Hanai T, Matsui H, et al. Hand-assisted laparoscopic function: preserving and radical gastrectomies for advanced-stage proximal gastric cancer. J Am Coll Surg. 2004;199:508-15.

16. Carboni F, Lepiane P, Santoro R, Mancini P, Lorusso R, Santoro E. Laparoscopic surgery for gastric cancer: preliminary experience. Gastric Cancer. 2005;8:75-7.

17. Azagra JS, Ibanez-Aguirre JF, Goergen M, Ceuterick M, Bordas-Rivas JM, Almendral-Lopez ML, et al. Long-term results of laparoscopic extended surgery in advanced gastric cancer: a series of 101 patients. Hepatogastroenterology. 2006;53:304-8.

18. Ibanez Aguirre FJ, Azagra JS, Erro Azcarate ML, Goergen M, Rico Selas P, Moreno Elola-Olaso A, et al. Laparoscopic gastrectomy for gastric adenocarcinoma. Long-term results. Revista Espanola de Enfermedades Digestivas 2006;98:491-500.

19. Huscher CG, Mingoli A, Sgarzini G, Brachini G, Binda B, Di Paola M, et al. Totally laparoscopic total and subtotal gastrectomy with extended lymph node dissection for early and advanced gastric cancer: early and long-term results of a 100-patient series. Am J Surg. 2007;194:839-44 (discussion 844).

20. Allieta R, Nardi M Jr, Brachet-Contul R, Millo P, Fabozzi M, Cornaglia $\mathrm{S}$, et al. Laparoscopic gastrectomy for treatment of advanced gastric cancer: preliminary experience on 38 cases. Minerva Chir. 2009;64:445-56.

21. Hwang SH, Park J, Jee YS, Kim MC, Kim HH, Lee HJ, et al. Actual 3-year survival after laparoscopy-assisted gastrectomy for gastric cancer. Arch Surg. 2009;144:559-64 (discussion 565).

22. Lee J, Kim W. Long-term outcomes after laparoscopy-assisted gastrectomy for advanced gastric cancer: analysis of consecutive 106 experiences. J Surg Oncol. 2009;100:693-8.

23. Tokunaga M, Hiki N, Fukunaga T, Nohara K, Katayama H, Akashi Y, et al. Laparoscopy-assisted distal gastrectomy with D2 lymph node dissection following standardization: a preliminary study. J Gastrointest Surg. 2009;13:1058-63.

24. Song J, Lee HJ, Cho GS, Han SU, Kim MC, Ryu SW, et al. Recurrence following laparoscopy-assisted gastrectomy for gastric cancer: a multicenter retrospective analysis of 1,417 patients. Ann Surg Oncol. 2010;17:1777-86.

25. Yoshimura F, Inaba K, Kawamura Y, Ishida Y, Taniguchi K, Isogaki J, et al. Clinical outcome and clinicopathological characteristics of recurrence after laparoscopic gastrectomy for advanced gastric cancer. Digestion. 2011;83:184-90.

26. Kim KH, Kim MC, Jung GJ, Kim HH. Long-term outcomes and feasibility with laparoscopy-assisted gastrectomy for gastric cancer. J Gastric Cancer. 2012;12:18-25.

27. Lee JH, Ahn SH, Park do J, Kim HH, Lee HJ, Yang HK. Laparoscopic total gastrectomy with D2 lymphadenectomy for advanced gastric cancer. World J Surg. 2012;36:2394-9.

28. Pak KH, Hyung WJ, Son T, Obama K, Woo Y, Kim HI, et al. Long-term oncologic outcomes of 714 consecutive laparoscopic gastrectomies for gastric cancer: results from the 7-year experience of a single institute. Surg Endosc. 2012;26:130-6.

29. Park do J, Han SU, Hyung WJ, Kim MC, Kim W, Ryu SY, et al. Long-term outcomes after laparoscopy-assisted gastrectomy for advanced gastric cancer: a large-scale multicenter retrospective study. Surg Endosc. 2012;26:1548-53.

30. Corcione F, Pirozzi F, Cuccurullo D, Angelini P, Cimmino V, Settembre A. Laparoscopic total gastrectomy in gastric cancer: our experience in 92 cases. Minim Invasive Therapy Allied Technol. 2013;22:271-8.

31. Fukunaga T, Hiki N, Kubota T, Nunobe S, Tokunaga M, Nohara $\mathrm{K}$, et al. Oncologic outcomes of laparoscopy-assisted distal gastrectomy for gastric cancer. Ann Surg Oncol. 2013;20:2676-82.

32. Lee J, Kim W. Clinical experience of 528 laparoscopic gastrectomies on gastric cancer in a single institution. Surgery (St. Louis). 2013;153:611-8.

33. Lee JH, Son SY, Lee CM, Ahn SH, Park do J, Kim HH. Morbidity and mortality after laparoscopic gastrectomy for advanced gastric cancer: results of a phase II clinical trial. Surg Endosc. 2013;27:2877-85.

34. Saeki H, Oki E, Tsuda Y, Ando K, Hiyoshi Y, Itoh S, et al. Relevance of totally laparoscopic gastrectomy for patients with advanced gastric cancer. Fukuoka Igaku Zasshi Hukuoka Acta Med. 2013;104:405-12.

35. Hu Y, Ying M, Huang C, Wei H, Jiang Z, Peng X, et al. Oncologic outcomes of laparoscopy-assisted gastrectomy for 
advanced gastric cancer: a large-scale multicenter retrospective cohort study from China. Surg Endosc. 2014;28:2048-56.

36. Zhang GT, Song YC, Zhang XD. Hand-assisted laparoscopic total gastrectomy with regional lymph node dissection for advanced gastric cancer. Surg Laparosc Endosc Percutaneous Tech. 2014;24:e78-84.

37. Adachi Y, Shiraishi N, Shiromizu A, Bandoh T, Aramaki M, Kitano S. Laparoscopy-assisted Billroth I gastrectomy compared with conventional open gastrectomy. Arch Surg. 2000;135:806-10.

38. Weber KJ, Reyes CD, Gagner M, Divino CM. Comparison of laparoscopic and open gastrectomy for malignant disease. Surg Endosc. 2003;17:968-71.

39. Dulucq JL, Wintringer P, Stabilini C, Solinas L, Perissat J, Mahajna A. Laparoscopic and open gastric resections for malignant lesions: a prospective comparative study. Surg Endosc. 2005;19:933-8.

40. Huscher CG, Mingoli A, Sgarzini G, Sansonetti A, Di Paola M, Recher A, et al. Laparoscopic versus open subtotal gastrectomy for distal gastric cancer: five-year results of a randomized prospective trial. Ann Surg. 2005;241:232-7.

41. Noshiro H, Nagai E, Shimizu S, Uchiyama A, Tanaka M. Laparoscopically assisted distal gastrectomy with standard radical lymph node dissection for gastric cancer. Surg Endosc. 2005;19:1592-6.

42. Varela JE, Hiyashi M, Nguyen T, Sabio A, Wilson SE, Nguyen NT. Comparison of laparoscopic and open gastrectomy for gastric cancer. Am J Surg. 2006;192:837-42.

43. Ziqiang W, Feng Q, Zhimin C, Miao W, Lian Q, Huaxing L, et al. Comparison of laparoscopically assisted and open radical distal gastrectomy with extended lymphadenectomy for gastric cancer management. Surg Endosc. 2006;20:1738-43.

44. Pugliese R, Maggioni D, Sansonna F, Scandroglio I, Ferrari GC, Di Lernia S, et al. Total and subtotal laparoscopic gastrectomy for adenocarcinoma. Surg Endosc. 2007;21:21-7.

45. Kawamura H, Homma S, Yokota R, Yokota K, Watarai H, Hagiwara $M$, et al. Inspection of safety and accuracy of D2 lymph node dissection in laparoscopy-assisted distal gastrectomy. World J Surg. 2008;32:2366-70.

46. Kiyama T, Fujita I, Kanno H, Tani A, Yoshiyuki T, Kato S, et al. Laparoscopy-assisted distal gastrectomy for gastric cancer. J Gastrointest Surg. 2008;12:1807-11.

47. Du XH, Li R, Chen L, Shen D, Li SY, Guo Q. Laparoscopyassisted D2 radical distal gastrectomy for advanced gastric cancer: initial experience. Chin Med J. 2009;122:1404-7.

48. Strong VE, Devaud N, Allen PJ, Gonen M, Brennan MF, Coit D. Laparoscopic versus open subtotal gastrectomy for adenocarcinoma: a case-control study. Ann Surg Oncol. 2009;16:1507-13.

49. Huang JL, Wei HB, Zheng ZH, Wei B, Chen TF, Huang Y, et al. Laparoscopy-assisted D2 radical distal gastrectomy for advanced gastric cancer. Dig Surg. 2010;27:291-6.

50. Kim HH, Hyung WJ, Cho GS, Kim MC, Han SU, Kim W, et al. Morbidity and mortality of laparoscopic gastrectomy versus open gastrectomy for gastric cancer: an interim report-a phase III multicenter, prospective, randomized trial (KLASS trial). Ann Surg. 2010;251:417-20.

51. Ikeda O, Sakaguchi Y, Toh Y, Oogaki K, Oki E, Minami K, et al. Evaluation of oncological adequacy of laparoscopic distal gastrectomy with special attention to lymph node dissection: a comparison with conventional open gastrectomy. Hepatogastroenterology. 2012;59:627-32.

52. Siani LM, Ferranti F, De Carlo A, Quintiliani A. Completely laparoscopic versus open total gastrectomy in stage I-III/C gastric cancer: safety, efficacy and five-year oncologic outcome. Minerva Chir. 2012;67:319-26.
53. Zhao XF, Jeong O, Jung MR, Ryu SY, Park YK. A propensity score-matched case-control comparative study of laparoscopic and open extended (D2) lymph node dissection for distal gastric carcinoma. Surg Endosc. 2013;27:2792-800.

54. Lee SR, Kim HO, Son BH, Shin JH, Yoo CH. Laparoscopicassisted total gastrectomy versus open total gastrectomy for upper and middle gastric cancer in short-term and long-term outcomes. Surg Laparosc Endosc Percutaneous Tech. 2014;24:277-82.

55. Li H, Han X, Su L, Zhu W, Xu W, Li K, et al. Laparoscopic radical gastrectomy versus traditional open surgery in elderly patients with gastric cancer: benefits and complications. Mol Clin Oncol. 2014;2:530-4.

56. Nam BH, Kim YW, Reim D, Eom BW, Yu WS, Park YK, et al. laparoscopy assisted versus open distal gastrectomy with D2 lymph node dissection for advanced gastric cancer: design and rationale of a phase II randomized controlled multicenter trial (COACT 1001). J Gastric Cancer. 2013;13:164-71.

57. Kim HI, Hur H, Kim YN, Lee HJ, Kim MC, Han SU, et al. Standardization of D2 lymphadenectomy and surgical quality control (KLASS-02-QC): a prospective, observational, multicenter study [NCT01283893]. BMC Cancer. 2014;14:209.

58. Cai J, Zhang C, Zhang H, Zhao T, Lv B, Gao C, et al. Open versus laparoscopy-assisted D2 radical gastrectomy in advanced upper gastric cancer: a retrospective cohort study. Hepatogastroenterology. 2013;60:1805-8.

59. Lin J, Huang C, Zheng C, Li P, Xie J, Wang J, et al. A matched cohort study of laparoscopy-assisted and open total gastrectomy for advanced proximal gastric cancer without serosa invasion. Chin Med J. 2014;127:403-7.

60. Tanimura S, Higashino M, Fukunaga Y, Kishida S, Nishikawa M, Ogata A, et al. Laparoscopic distal gastrectomy with regional lymph node dissection for gastric cancer. Surg Endosc. 2005;19:1177-81.

61. Kang KC, Cho GS, Han SU, Kim W, Kim HH, Kim MC, et al. Comparison of Billroth I and Billroth II reconstructions after laparoscopy-assisted distal gastrectomy: a retrospective analysis of large-scale multicenter results from Korea. Surg Endosc. 2011;25:1953-61.

62. Liu J, Yang K, Chen XZ, Dai B, Zhang B, Chen ZX, et al. Quality of life following laparoscopic-assisted distal gastrectomy for gastric cancer. Hepatogastroenterology. 2012;59:2207-12.

63. Yu J, Hu J, Huang C, Ying M, Peng X, Wei H, et al. The impact of age and comorbidity on postoperative complications in patients with advanced gastric cancer after laparoscopic D2 gastrectomy: results from the Chinese laparoscopic gastrointestinal surgery study (CLASS) group. Eur J Surg Oncol. 2013;39:1144-9.

64. Lee SI, Choi YS, Park DJ, Kim HH, Yang HK, Kim MC. Comparative study of laparoscopy-assisted distal gastrectomy and open distal gastrectomy. J Am Coll Surg. 2006;202:874-80.

65. Hur H, Jeon HM, Kim W. Laparoscopy-assisted distal gastrectomy with D2 lymphadenectomy for T2b advanced gastric cancers: three years' experience. J Surg Oncol. 2008;98:515-9.

66. Hwang SI, Kim HO, Yoo CH, Shin JH, Son BH. Laparoscopicassisted distal gastrectomy versus open distal gastrectomy for advanced gastric cancer. Surg Endosc. 2009;23:1252-8.

67. Du J, Zheng J, Li Y, Li J, Ji G, Dong G, et al. Laparoscopyassisted total gastrectomy with extended lymph node resection for advanced gastric cancer: reports of 82 cases. Hepatogastroenterology. 2010;57:1589-94.

68. Cai J, Wei D, Gao CF, Zhang CS, Zhang H, Zhao T. A prospective randomized study comparing open versus laparoscopy-assisted D2 radical gastrectomy in advanced gastric cancer. Dig Surg. 2011;28:331-7. 
69. Jeong SH, Lee YJ, Park ST, Choi SK, Hong SC, Jung EJ, et al. Risk of recurrence after laparoscopy-assisted radical gastrectomy for gastric cancer performed by a single surgeon. Surg Endosc. 2011;25:872-8.

70. Scatizzi M, Kroning KC, Lenzi E, Moraldi L, Cantafio S, Feroci F. Laparoscopic versus open distal gastrectomy for locally advanced gastric cancer: a case-control study. Updates Surg. 2011;63:17-23.

71. Shuang J, Qi S, Zheng J, Zhao Q, Li J, Kang Z, et al. A casecontrol study of laparoscopy-assisted and open distal gastrectomy for advanced gastric cancer. J Gastrointest Surg. 2011;15:57-62.

72. Sica GS, Iaculli E, Biancone L, Di Carlo S, Scaramuzzo R, Fiorani C, et al. Comparative study of laparoscopic vs. open gastrectomy in gastric cancer management. World J Gastroenterol. 2011;17:4602-6.

73. Zhao Y, Yu P, Hao Y, Qian F, Tang B, Shi Y, et al. Comparison of outcomes for laparoscopically assisted and open radical distal gastrectomy with lymphadenectomy for advanced gastric cancer. Surg Endosc. 2011;25:2960-6.

74. Chen QY, Huang CM, Lin JX, Zheng CH, Li P, Xie JW, et al. Laparoscopy-assisted versus open D2 radical gastrectomy for advanced gastric cancer without serosal invasion: a case control study. World J Surg Oncol. 2012;10:248.

75. Chun HT, Kim KH, Kim MC, Jung GJ. Comparative study of laparoscopy-assisted versus open subtotal gastrectomy for pT2 gastric cancer. Yonsei Med J. 2012;53:952-9.

76. Hamabe A, Omori T, Tanaka K, Nishida T. Comparison of longterm results between laparoscopy-assisted gastrectomy and open gastrectomy with D2 lymph node dissection for advanced gastric cancer. Surg Endosc. 2012;26:1702-9.

77. Kim KH, Kim MC, Jung GJ, Choi HJ, Jang JS, Kwon HC. Comparative analysis of five-year survival results of laparoscopy-assisted gastrectomy versus open gastrectomy for advanced gastric cancer: a case-control study using a propensity score method. Dig Surg. 2012;29:165-71.

78. MacLellan SJ, MacKay HJ, Ringash J, Jacks L, Kassam Z, Conrad $\mathrm{T}$, et al. Laparoscopic gastrectomy for patients with advanced gastric cancer produces oncologic outcomes similar to those for open resection. Surg Endosc. 2012;26:1813-21.

79. Moisan F, Norero E, Slako M, Varas J, Palominos G, Crovari F, et al. Completely laparoscopic versus open gastrectomy for early and advanced gastric cancer: a matched cohort study. Surg Endosc. 2012;26:661-72.

80. Sato H, Shimada M, Kurita N, Iwata T, Nishioka M, Morimoto $\mathrm{S}$, et al. Comparison of long-term prognosis of laparoscopyassisted gastrectomy and conventional open gastrectomy with special reference to D2 lymph node dissection. Surg Endosc. 2012;26:2240-6.

81. Bo T, Peiwu Y, Feng Q, Yongliang Z, Yan S, Yingxue H, et al. Laparoscopy-assisted vs. open total gastrectomy for advanced gastric cancer: long-term outcomes and technical aspects of a case-control study. J Gastrointest Surg 2013;17:1202-1208.

82. Fang F, Han F, Ding YL, Wang HJ. Comparison of laparoscopyassisted surgery and laparotomy for treating locally advanced distal gastric antral cancer. Exp Ther Med. 2013;6:753-8.

83. Gordon AC, Kojima K, Inokuchi M, Kato K, Sugihara K. Longterm comparison of laparoscopy-assisted distal gastrectomy and open distal gastrectomy in advanced gastric cancer. Surg Endosc. 2013;27:462-70.

84. Li ZX, Xu YC, Lin WL, Chen J, Wu HY. Therapeutic effect of laparoscopy-assisted D2 radical gastrectomy in 106 patients with advanced gastric cancer. J BUON. 2013;18:689-94.

85. Lin JX, Huang CM, Zheng CH, Li P, Xie JW, Wang JB, et al. Laparoscopy-assisted gastrectomy with D2 lymph node dissection for advanced gastric cancer without serosa invasion: a matched cohort study from South China. World J Surg Oncol. 2013;11:4.

86. Shinohara T, Satoh S, Kanaya S, Ishida Y, Taniguchi K, Isogaki $\mathrm{J}$, et al. Laparoscopic versus open D2 gastrectomy for advanced gastric cancer: a retrospective cohort study. Surg Endosc. 2013;27:286-94.

87. Yamanaka N, Nagai E, Ohuchida K, Ueda J, Toma H, Shimizu $\mathrm{S}$, et al. Feasibility of laparoscopic gastrectomy for advanced gastric cancer with positive peritoneal cytology. Surg Today. 2013;43:859-64.

88. Fang C, Hua J, Li J, Zhen J, Wang F, Zhao Q, et al. Comparison of long-term results between laparoscopy-assisted gastrectomy and open gastrectomy with D2 lymphadenectomy for advanced gastric cancer. Am J Surg. 2014;208:391-6.

89. Lee JH, Lee CM, Son SY, Ahn SH, Park do J, Kim HH. Laparoscopic versus open gastrectomy for gastric cancer: longterm oncologic results. Surgery (St. Louis). 2014;155:154-64.

90. Fuchs KH. Minimally invasive surgery. Endoscopy. 2002;34:154-9.

91. Blackmore AE, Wong MT, Tang CL. Evolution of laparoscopy in colorectal surgery: an evidence-based review. World J Gastroenterol: WJG. 2014;20:4926-33.

92. Son T, Kwon IG, Hyung WJ. Minimally invasive surgery for gastric cancer treatment: current status and future perspectives. Gut Liver. 2014;8:229-36.

93. Ansari D, Gianotti L, Schroder J, Andersson R. Fast-track surgery: procedure-specific aspects and future direction. Langenbeck's Arch Surg. 2013;398:29-37.

94. Chen ZX, Liu AH, Cen Y. Fast-track program vs. traditional care in surgery for gastric cancer. World $\mathrm{J}$ Gastroenterol. 2014;20:578-83.

95. Amin AT, Gabr A, Abbas H. Laparoscopy assisted distal gastrectomy for T1 to T2 stage gastric cancer: a pilot study of three ports technique. Updates Surg 2015;67:69-74

96. Campo R, Puga M, Meier Furst R, Wattiez A, De Wilde RL. Excellence needs training: "Certified programme in endoscopic surgery." Facts Views Vis ObGyn 2014;6:240-244.

97. Wottawa CR, Cohen JR, Fan RE, Bisley JW, Culjat MO, Grundfest WS, et al. The role of tactile feedback in grip force during laparoscopic training tasks. Surg Endosc. 2013;27:1111-8.

98. Hyung WJ, Song C, Cheong JH, Choi SH, Noh SH. Factors influencing operation time of laparoscopy-assisted distal subtotal gastrectomy: analysis of consecutive 100 initial cases. Eur J Surg Oncol. 2007;33:314-9.

99. Hu WG, Ma JJ, Zang L, Xue P, Xu H, Wang ML, et al. Learning curve and long-term outcomes of laparoscopy-assisted distal gastrectomy for gastric cancer. J Laparoendosc Adv Surg Tech Part A. 2014;24:487-92.

100. Kim HG, Park JH, Jeong SH, Lee YJ, Ha WS, Choi SK, et al. Totally laparoscopic distal gastrectomy after learning curve completion: comparison with laparoscopy-assisted distal gastrectomy. J Gastric Cancer. 2013;13:26-33.

101. Gabriel L, Beriot-Mathiot A. Hospitalization stay and costs attributable to Clostridium difficile infection: a critical review. J Hosp Infect. 2014;88:12-21.

102. Lippi G, Favaloro EJ, Cervellin G. Prevention of venous thromboembolism: focus on mechanical prophylaxis. Semin Thromb Hemost. 2011;37:237-51.

103. Deng JY, Liang H. Clinical significance of lymph node metastasis in gastric cancer. World J Gastroenterol. 2014;20:3967-75.

104. Hsu JT, Lin CJ, Sung CM, Yeh HC, Chen TH, Chen TC, et al. Prognostic significance of the number of examined lymph nodes in node-negative gastric adenocarcinoma. Eur J Surg Oncol. 2013;39:1287-93.

105. Lee SS, Kim IH. Are there any disbenefits to patients in choosing laparoscopic gastrectomy by an expert in open 
gastrectomy? Aspects of surgical outcome and radicality of lymphadenectomy. Chin Med J. 2013;126:4247-53.

106. Yoon SS, Yang HK. Lymphadenectomy for gastric adenocarcinoma: should west meet east? Oncologist. 2009;14:871-82.

107. de Steur WO, Dikken JL, Hartgrink HH. Lymph node dissection in resectable advanced gastric cancer. Dig Surg. 2013;30:96-103.

108. Eberlin LS, Tibshirani RJ, Zhang J, Longacre TA, Berry GJ, Bingham DB, et al. Molecular assessment of surgical-resection margins of gastric cancer by mass-spectrometric imaging. Proc Natl Acad Sci USA. 2014;111:2436-41.

109. Liang Y, Ding X, Wang X, Wang B, Deng J, Zhang L, et al. Prognostic value of surgical margin status in gastric cancer patients. ANZ J Surg 2014. doi:10.1111/ans.12515

110. Woo JW, Ryu KW, Park JY, Eom BW, Kim MJ, Yoon HM, et al. Prognostic impact of microscopic tumor involved resection margin in advanced gastric cancer patients after gastric resection. World J Surg. 2014;38:439-46.

111. Kim BS, Oh ST, Yook JH, Kim HS, Lee IS, Kim BS. Appropriate gastrectomy resection margins for early gastric carcinoma. J Surg Oncol. 2014;109:198-201.

112. Deng J, Zhang R, Pan Y, Ding X, Cai M, Liu Y, et al. Tumor size as a recommendable variable for accuracy of the prognostic prediction of gastric cancer: a retrospective analysis of 1,521 patients. Ann Surg Oncol. 2015;22:565-72.

113. Chen K, Xu XW, Mou YP, Pan Y, Zhou YC, Zhang RC, et al. Systematic review and meta-analysis of laparoscopic and open gastrectomy for advanced gastric cancer. World J Surg Oncol. 2013; 11:182.

114. Nduka CC, Monson JR, Menzies-Gow N, Darzi A. Abdominal wall metastases following laparoscopy. $\mathrm{Br} \quad \mathrm{J}$ Surg. 1994;81:648-52.

115. Song J, Kim E, Mobley J, Vemana G, Tanagho Y, Vetter J, et al. Port site metastasis after surgery for renal cell carcinoma: harbinger of future metastasis. J Urol. 2014;192:364-8.

116. Sakurai K, Tanaka H, Lee T, Muguruma K, Kubo N, Yashiro M, et al. Port site metastasis after laparoscopic-assisted distal gastrectomy (LADG). Int Surg. 2013;98:363-6.

117. Karthik S, Augustine AJ, Shibumon MM, Pai MV. Analysis of laparoscopic port site complications: a descriptive study. J Minim Access Surg. 2013;9:59-64. 